\title{
Perrine Galand-Hallyn, Michel de l'Hospital à l'école de Salmon Macrin dans les Carmina
}

\section{Filippo Fonio}

\section{(2) OpenEdition}

1 Journals

\section{Edizione digitale}

URL: https://journals.openedition.org/studifrancesi/39093

DOI: 10.4000/studifrancesi.39093

ISSN: 2421-5856

\section{Editore}

Rosenberg \& Sellier

\section{Edizione cartacea}

Data di pubblicazione: 1 décembre 2004

Paginazione: 347

ISSN: 0039-2944

\section{Notizia bibliografica digitale}

Filippo Fonio, «Perrine Galand-Hallyn, Michel de l'Hospital à l'école de Salmon Macrin dans les Carmina», Studi Francesi [Online], 143 (XLVIII | II) | 2004, online dal 30 novembre 2015, consultato il 19 mai 2021. URL: http://journals.openedition.org/studifrancesi/39093 ; DOI: https://doi.org/10.4000/studifrancesi. 39093

Questo documento è stato generato automaticamente il 19 mai 2021.

\section{(c) (1)}

Studi Francesi è distribuita con Licenza Creative Commons Attribuzione - Non commerciale - Non opere derivate 4.0 Internazionale. 


\title{
Perrine Galand-Hallyn, Michel de l'Hospital à l'école de Salmon Macrin dans les Carmina
}

\author{
Filippo Fonio
}

\section{NOTIZIA}

PERRINE GALAND-HALLYN, Michel de l'Hospital à l'école de Salmon Macrin dans les Carmina, "Bibliothèque d'Humanisme et Renaissance", LXV, 1 (2003), pp. 7-50.

1 Il presente studio si ricollega ai seminari tenutisi all'École Pratique des Hautes Études nel periodo 2000-2002, sui Carmina di Michel de l'Hospital. L'autrice sta inoltre preparando un'edizione critica dell'opera, provvista di traduzione e commento.

2 L'analisi in questione è finalizzata a mettere in evidenza i rapporti fra il poeta-giurista Michel de l'Hospital (1505-1573) e Jean Salmon, detto Macrin (1490-1557), il più importante poeta in lingua latina della generazione di Marot. All'incontro fra i due, avvenuto alla metà circa degli anni Quaranta, è in parte dovuto l'esordio poetico di Michel de l'Hospital, i cui Carmina, epistole in esametri sul modello oraziano, constano di sette libri, più un ottavo (Tumuli) e un nono (Mantissa) aggiunto all'ed. $1732 \mathrm{e}$ presente nel ms. di Gand. L'autrice si occupa in particolare dei componimenti programmatici e metaletterari del poeta, osservando nelle sue varie fasi la creazione di un ethos dell'isolamento e della marginalità, che parte dal tema della vocazione poetica, accompagnata dall'apprendistato, per approdare a una rilettura personale dell'ideale oraziano della mediocritas. Diversi sono i motivi comuni ai due poeti, anche in virtù della scelta di uno stesso modello, Orazio appunto (quello delle Odi per Salmon Macrin, quello delle Epistole per Michel de l'Hospital). Fra gli altri, la dicotomia fra esercizio poetico e carriera-guadagno; la recusatio e il ripiegamento verso la lirica d'occasione, accompagnato però dalla speranza che le generazioni future tornino all'epica, come già avviene oltralpe; il precetto, desunto dall'Ars poetica oraziana, di adattare la materia e 
l'impresa che ci si prefigge all'ingenium, e più in generale un andamento fra l'epidittico e il parenetico, modi sentiti come strettamente connessi; la polemica nei confronti dei poeti modernisti, di gusto epigrammatico. Soprattutto, entrambi i poeti vagheggiano un ripiegamento negli affetti domestici e nei valori quotidiani, sulla base del rapporto erasmiano famiglia-Stato nei termini microcosmo-macrocosmo, professando nel contempo la propria fede nell'interiorità e nella parola etica. In definitiva, "malgré leur différence évidente de condition et de tempérament, L'Hospital a pu trouver chez son ami Macrin plusieurs stratégies d'écriture qui s'adaptaient à sa propre marginalité et lui permirent de le prendre pour guide [...]», p. 43.

In appendice è l'edizione del carmen IX, 13, imitazione macriniana. 